\title{
A 5-year retrospective study of demographic, anamnestic, and clinical factors related to psychiatric hospitalizations of adolescent patients
}

This article was published in the following Dove Press journal:

Neuropsychiatric Disease and Treatment

18 January 2016

Number of times this article has been viewed

\section{Rosaria Di Lorenzo' \\ Nina Cimino² \\ Elena Di Pietro ${ }^{3}$ \\ Gabriella Pollutri ${ }^{4}$ \\ Vittoria Neviani ${ }^{5}$ \\ Paola Ferri ${ }^{2}$}

'Service of Psychiatric Diagnosis and Treatment, Department of Mental Health, AUSL Modena, Modena, ${ }^{2} \mathrm{School}$ of Nursing, University of Modena and Reggio Emilia, ${ }^{3}$ School of Neuro-Psychiatry, ${ }^{4}$ School of Psychiatry, University of Modena and Reggio Emilia, "“"The Medlar", Villa Igea Hospital, Modena, Italy
Correspondence: Rosaria Di Lorenzo Mental Health Department, SPDCModena Centro, NOCSAE, via P. Giardini n I355, 4 I I 26 Baggiovara Modena, Italy Email saradilorenzol@alice.it
Background: Psychiatric emergencies of children and adolescents have greatly increased during the last years, but this phenomenon has not been studied in detail. The aim of this study was to analyze the correlation between acute psychiatric hospitalizations of adolescents and selected variables to highlight risk factors for psychiatric emergencies.

Methods: This retrospective research was conducted in the acute psychiatric public ward, Service of Psychiatric Diagnosis and Treatment (SPDT), and in the residential facility for adolescents, "The Medlar", located in Modena. The sample was constituted by all adolescent patients ( $\mathrm{n}=101$, age range $14-18)$ who had acute hospitalizations $(\mathrm{n}=140)$ in SPDT and had been successively transferred to "The Medlar" ( $n=83$ ), from February 2, 2010 to January 31, 2015. From clinical charts, we extracted demographic and anamnestic characteristics of patients and clinical variables related to hospitalizations. Data were statistically analyzed.

Results: Sixty-one percent of our patients lived with one divorced parent, with adoptive or immigrant family, or in institutions; $51 \%$ had experienced stressful events during childhood; $81 \%$ had a normal intellective level, but only $6 \%$ presented regular school performance. Parental psychiatric illness was negatively related, in a statistically significantly way, with onset age of adolescent mental disorders (coefficient $-2.28,95 \%$ confidence interval $[\mathrm{CI}]:-3.53$ to 1.01 , $P<0.001$, single linear regression; odds ratio: $4.39,95 \%$ CI: $1.43-13.47, P<0.010$, single logistic regression). The most frequent reasons for admission were aggressive behavior in males and suicide risk in females $(P=0.002)$. The most frequent psychiatric diagnosis at SPDT discharge was "conduct disorder", more frequent in males, followed by "adjustment disorder", more frequent in females $(P=0.001)$. In SPDT, the adolescent hospitalizations progressively increased fivefold at the end of the observation period.

Conclusion: Our results overlap the worldwide trend of increasing adolescent psychiatric hospitalizations, suggest risk factors like parental psychiatric illness and early life stressful events, and highlight the different prevalence of aggressiveness and suicide in males and females.

Keywords: psychiatric hospitalizations, adolescent patients, stressful events, mental disorders, suicide risk

\section{Introduction}

Most authors have highlighted that psychiatric emergencies of children and adolescents are globally widespread and have estimated their exponential increase in the coming decades. ${ }^{1-3}$ Several studies reported the difficulty in collecting specific information on this topic, and therefore, in formulating recommendations for psychiatric hospitalizations of pediatric patients. ${ }^{4-6}$ Canadian and American studies have highlighted that the prevalence of mental illness among children and adolescents ranges between $15 \%$ and $20 \%$, estimating an increase of $50 \%$ by $2020 .{ }^{1,7}$ Currently, psychiatric visits 
for pediatric patients in emergency account for $\sim 1.6 \%$ of all emergency room pediatric visits in the US and $1 \%$ in Canada. In the US, among 100,000 admissions per year of patients, aged between six and 18, 418 psychiatric admissions were recorded. ${ }^{8-11}$ The number of psychiatric emergency consultations of pediatric patients has significantly increased in Europe also, ${ }^{12-14}$ in particular in Italy, ${ }^{15}$ where an increase of $38 \%$ in psychiatric visits in emergency room has been recorded from 2001 to $2004^{16}$ for the following causes: conduct disorders, substance and alcohol abuse, severe anxiety disorders, and eating disorders. ${ }^{17}$ Self- or hetero-aggressive behavior is one of the most frequent reasons for psychiatric hospitalization of adolescents, probably because it can be difficult to control in family or community environments. ${ }^{18-20}$ The aggressive behavior can be related to many different psychiatric disorders, such as conduct, psychotic, bipolar, and eating disorders, or can represent an extreme reaction to difficult environmental situations. ${ }^{21-23}$ Among risk factors, maternal drug and alcohol abuse during pregnancy as well as growth disorders during late fetal period and birth injuries is often correlated with early development of aggressive behavior in children. ${ }^{16}$ Many neuropsychological deficits in executive functions, such as self-regulation, inhibitory control, abstract reasoning, problem-solving, sustained attention-organization, and work planning, have been evidenced as important predictors of violent behavior in childhood. ${ }^{16}$ Negative family atmosphere, characterized by poor affect and unstable relationships, which induce insecure attachment of children, could be related to the development of aggressiveness. ${ }^{16,24}$ Most studies have reported that domestic violence, parental abandonment, and physical/sexual abuse represent important triggers for aggressive behavior in childhood and adolescence. ${ }^{16,24,25}$ In particular, children who suffered from incest, sexual abuse, or physical abuse can be more vulnerable to early psychosis. ${ }^{23,26,27} \mathrm{~A}$ negative and hostile school environment can contribute to the development of aggressive behavior, especially in those children who are victims of bullying. ${ }^{16}$ Also, some socioeconomic factors, which induce social maladjustment, can increase the need for psychiatric emergency consultations. ${ }^{16}$ Children and adolescents who belong to families of second- and thirdgeneration immigrants can be more vulnerable individuals, frequently requiring acute psychiatric intervention at emergency departments. ${ }^{21,22}$ In adolescents, the use of alcohol and drugs could be related to both aggressive and suicidal behaviors. ${ }^{15,27-30}$ During adolescence, some mental disorders can become more evident due to this critical phase of transition. As indicated by all guidelines, it is important to diagnose psychiatric disorders at their onset in order to begin treatment as soon as possible, since psychiatric disorders which begin in adolescence rarely have spontaneous remission. ${ }^{31} \mathrm{~A}$ recent review has put in evidence that first onset of mental disorders usually occurs in childhood or adolescence, although treatment typically does not occur until a number of years later. ${ }^{31}$ Another author has more recently confirmed that adult mental health disorders most frequently begin by adolescence. ${ }^{31,32}$ There are many shared criteria of appropriateness concerning psychiatric hospitalizations of adolescents. ${ }^{33-37}$ One of the best known classifications of adolescent psychiatric emergencies, which has been developed by Edelsohn and Gomez, ${ }^{37}$ divides the appropriateness of admission into four groups: 1) potential threat to life and/or to others; 2) state of high distress that requires urgent action, without an urgent threat to life; 3 ) serious conditions that require prompt but not immediate intervention; 4) "false alarms". Similar to the American Academy of Child and Adolescent Psychiatry, ${ }^{33}$ the guidelines of the Royal College of Psychiatrists ${ }^{35}$ indicate the need for psychiatric admission in the following situations: acute clinical situation which cannot be managed in outpatient care settings and destructive behavior toward himself or others. The guidelines for acute psychiatric hospitalization of children from the American Psychiatric Association ${ }^{34}$ indicate the following eleven clinical situations: severe disorders in acute phase; all debut psychiatric disorders; major depressive disorder; suicide attempts; intoxication and/or withdrawal in addiction disorders; untreatable eating disorders with severe risk to life; severe psychosomatic disorders; obsessivecompulsive or phobia disorders which induce disabling conditions; other conditions of chronic disability, like mental retardation or cognitive impairment, with impulsivity and state of agitation; personality disorders with anxiety and maladaptation; and posttraumatic stress disorders. In Italy, the Childhood and Adolescence Neuro-Psychiatry Service (CANPS) delivers multidisciplinary treatment programs in out- and inpatient care settings for children and adolescents with psychiatric problems. ${ }^{38}$ Among the Italian regions, the allocation of resources for CANPS is insufficient overall to ensure the dissemination and consolidation of out- and inpatient care services, according to a national report. ${ }^{39-43}$ From 2008 to 2012, in Italy, the psychiatric admissions of adolescent patients presented an increase of $12 \%$, but only a third of children or adolescents were hospitalized in CANPS facilities. $^{44,45}$

\section{Aim}

The aim of this study was to analyze the correlation between acute psychiatric hospitalization of adolescents and selected 
demographic and clinical variables, in order to highlight risk factors for psychiatric emergencies.

\section{Materials and methods Study design}

This retrospective research was conducted in the acute psychiatric ward Service of Psychiatric Diagnosis and Treatment (SPDT), located in the general hospital, Nuovo Ospedale Civile Sant'Agostino Estense of Modena, and in the residential facility for adolescents, "The Medlar", located in an accredited private hospital (Villa Igea) in Modena.

\section{Local organization of children and adolescent neuropsychiatric services}

The CANPS in Modena, which is part of Mental Health Department (Az-USL-Modena), is composed of a multiprofessional team divided into five areas of treatment: neurology, psychiatry, neuropsychology, autism, and mental retardation. Since 2010, two beds have been available for patients aged from 14 to 18 in a separate part of the public psychiatric ward SPDT of Modena, where patients can be hospitalized after consultation in emergency department. The local guidelines indicate that after a brief hospitalization in SPDT, patients can be transferred to the psychiatric facility for adolescents in Modena, "The Medlar". It is an accredited facility which accommodates eight patients aged from 14 to 18 years, suffering from major emotional disorders and/ or behavioral alterations that cannot be treated in outpatient setting. The multi-professional staff of "The Medlar" is directly connected with the referring therapeutics of CANPS and provides clinical intervention of short individual and family psychotherapy, rehabilitative activities, educational interventions, and drug treatments, tailored to the needs of patients and their families. In particular, the first week's stay at "The Medlar" is dedicated to observation of the patient with "low stimulation" activities. Afterwards, patients start structured programs aimed at the recognition of personal issues and disorder awareness, and in the meantime, at the regaining of adequate physical and cognitive performances. Many activities with the purposes described earlier are developed: music laboratory, biofeedback, theater performance (acting and set design), group and pet therapy, gardening, art workshop, and mindfulness. At discharge, the patient is sent back home or to a community with the consultation of both his general physician and referring psychiatrist of CANPS, in order to maintain an uninterrupted treatment.

\section{Sample}

It was constituted by all adolescent patients ( $\mathrm{n}=101$, age range 14-18 years) who accounted for acute hospitalizations $(n=140)$ in SPDT and were successively transferred to "The Medlar" (n=83), from February 2, 2010 to January 31, 2015. The start of study period was determined by the availability of two beds for adolescent patients (age range 14-18 years) in a separate part of the acute psychiatric ward SPDT of Modena, for voluntary and involuntary admissions. We collected this sample from the ward electronic medical record database.

\section{Selected variables}

From clinical charts, we extracted demographic and anamnestic characteristics of our adolescent patients (Table 1) and all the available clinical variables related to our sample's hospitalizations in SPDT and in "The Medlar" (Table 2).

Table I The selected demographic and anamnestic variables of our sample

\begin{tabular}{|c|c|}
\hline \multicolumn{2}{|l|}{ Demographic } \\
\hline Sex & Either male or female \\
\hline Age & In years $($ mean $\pm S D)$ \\
\hline Birth place & I) Italy; 2) Europe; 3) Non-Europe \\
\hline Family & $\begin{array}{l}\text { I) Biological Italian parents; 2) divorced parents; 3) adoptive parents; 4) no family; } \\
\text { 5) biological immigrant parents }\end{array}$ \\
\hline Education achieved School attendance & I) Primary school; 2) secondary school \\
\hline Education performance School performance & I) Regular/good; 2) low; 3) school abandonment \\
\hline \multicolumn{2}{|l|}{ Anamnestic } \\
\hline Parental disorders & I) None; 2) psychiatric diseases; 3) addictions; 4) other diseases \\
\hline Early life stressful events & $\begin{array}{l}\text { I) None; 2) parental abandonment, bereavement, and/or social maladjustment; } \\
\text { 3) economic problems; 4) more or other events }\end{array}$ \\
\hline Child abuse & I) None; 2) physical abuse; 3) sexual abuse; 4) other \\
\hline Intellective level & I) Normal; 2) lower in comparison to the range for age \\
\hline Onset age of psychiatric pathology & Years $($ mean $\pm S D)$ \\
\hline Psychiatric treatment period & Years $($ mean $\pm S D)$ \\
\hline
\end{tabular}

Abbreviation: SD, standard deviation. 
Table 2 The selected clinical variables of our sample's hospitalizations in SPDT and "The Medlar"

\begin{tabular}{ll}
\hline Clinical variables & I) Aggressive behavior; 2) risk of suicide; 3) acute psychotic decompensation; 4) substance abuse; \\
Reason for hospitalization & 5) depressive state; 6) psychosocial emergency; 7) running away; 8) other \\
Hospitalization modality & I) Voluntary treatment; 2) involuntary treatment \\
Admission modality & I) After ER consultant; 2) Transfer from "The Medlar" or from another ward; 3) After CANPS consultant \\
Aggressive behavior & I) None; 2) present; 3) severe with need for physical restraint and/or hospital security \\
Duration of hospitalization & Days (mean \pm SD) \\
Psychiatric diagnosis at SPDT & I) Psychiatric disorders related to substance abuse; 2) schizophrenia disorders and other psychoses; \\
discharge (ICD-9-CM) & 3) bipolar disorders; 4) anxiety disorders and dysthymia; 5) personality disorders; 6) substance \\
abuse; 7) eating disorders; 8) adjustment disorders; 9) conduct disorders; I0) neurodevelopmental disorders \\
Organic comorbidity & and mental retardation \\
Substance abuse in comorbidity & I) None; 2) present \\
Pharmacological therapy at & I) None; 2) alcohol; 3) stimulants (cocaine); 4) cannabinoids; 5) opioids; 6) cannabinoids and other substances \\
discharge & I) Typical antipsychotics; 2) Atypical antipsychotics; 3) Antidepressants; 4) Mood stabilizers; \\
Therapeutic compliance & 5) Benzodiazepines \\
Psychotherapy & I) None; 2) present; 3) discontinuous \\
Rehabilitive programs & I) None; 2) Individual; 3) Family therapy \\
Destination at discharge & I) None; 2) To general functioning; 3) To specific performances \\
\hline I) Home with CANPS care; 2) Day hospital of CANPS; 3) Community/protected facility; 4) Transfer to & another psychiatric ward or facility; 5) Other
\end{tabular}

Abbreviations: SPDT, Service of Psychiatric Diagnosis and Treatment; ER, emergency room; CANPS, Childhood and Adolescence Neuro-Psychiatry Service; SD, standard deviation; ICD-9-CM, International Classification of Diseases, 9th Revision, Clinical Modification, Italian Version of 2007.

The psychiatric diagnoses were in accordance with the International Classification of Diseases, 9th Revision, Clinical Modification, Italian Version of $2007,{ }^{46}$ used in SPDT.

\section{Statistical analysis}

We calculated absolute frequency and percentages for categorical variables, and mean and standard deviation (SD) for continuous variables. We evaluated the association between each variable and the sex of our adolescent patients by using the chi ${ }^{2}$ test for categorical data and Student's $t$-test for continuous data.

In our study, we considered the "age of psychiatric disorder onset" as dependent variable and applied the single and multiple linear regression to correlate it to the demographic, anamnestic, and clinical variables selected. The coefficient of regression and the respective $95 \%$ confidence interval were calculated for each variable category. A $P$-value $<0.05$ was considered statistically significant. Data were analyzed by using the statistical software STATA version $12 .{ }^{47}$

\section{Ethical approach}

The parents or legal guardians of our patients gave us informed consent at the beginning of hospitalizations in both SPDT and "The Medlar". This study was conducted in accordance with the principles of the Declaration of Helsinki (World Medical Association Declaration of Helsinki, 1964) and good clinical practice and was not sponsored by any pharmaceutical company. This study received ethical approval from the Institutional Review Board of Modena Health Trust.

\section{Results}

Our sample of patients was composed of 56 males and 45 females $(\mathrm{N}=101)$, with an average age slightly $<16$ years (15.99 $\pm 1.77 \mathrm{SD}$ ), which did not differ statistically significantly between the two sexes (Table 3). Only $39 \%$ of our patients lived in a family composed of both biological Italian parents, whereas the remaining cases presented family situations of separated parents (17\%), adoptive family (4\%), immigrant parents (23\%), or orphanages and/ or abandoned (18\%), with a statistically significant difference between males and females (Table 3). The majority of our sample did not report any parental disorder, which, if occurred, was mostly represented by psychiatric illness (21\%) (Table 3). Fifty-one percent of our patients had experienced abandonment, economic failure, social maladjustment, and other stressful events, whereas only a minority of them (12.75\%) had suffered from physical and/ or sexual abuse (Table 3).

The majority ( $89 \%$ ) of our patients presented normal intellective level according to range for age (Table 3). Concerning school attendance and performance, we have found a statistically significant difference between males, 
Table 3 The demographic and anamnestic variables of our patients $(n=|0|)$

\begin{tabular}{|c|c|c|c|c|}
\hline \multirow[t]{2}{*}{ Variables } & \multirow{2}{*}{$\frac{\text { Males }}{N=56(55 \%)}$} & \multirow{2}{*}{$\frac{\text { Females }}{N=45(45 \%)}$} & \multirow{2}{*}{$\frac{\text { Total }}{N=101(100 \%)}$} & \multirow[t]{2}{*}{ Statistical test } \\
\hline & & & & \\
\hline \multicolumn{5}{|l|}{ Age, mean \pm SD } \\
\hline Years & $16.27 \pm 1.34$ & $15.54 \pm 2.15$ & $15.99 \pm 1.77$ & Not stastically significant \\
\hline \multicolumn{5}{|l|}{ Birth place, n (\%) } \\
\hline I) Italy & $37(37)$ & $30(30)$ & $66(66)$ & Not stastically significant \\
\hline 2) Europe & $4(4)$ & $8(8)$ & $12(12)$ & \\
\hline 3) Non-Europe & $15(15)$ & 7 (7) & $22(22)$ & \\
\hline \multicolumn{5}{|l|}{ Family, n (\%) } \\
\hline I) Biological Italian parents & $25(25)$ & $14(14)$ & $39(39)$ & Pearson $\mathrm{chi}^{2}=12.13, P=0.016$ \\
\hline 2) Divorced parents & $7(7)$ & $10(10)$ & $17(17)$ & \\
\hline 3) Adoptive parents & $I(I)$ & $3(3)$ & $4(4)$ & \\
\hline 4) No family & $14(14)$ & $4(4)$ & $18(18)$ & \\
\hline 5) Biological immigrant parents & $9(9)$ & $14(14)$ & $23(23)$ & \\
\hline \multicolumn{5}{|l|}{ School attendance, n (\%)* } \\
\hline I) Primary school & $8(8)$ & II (I2) & $19(20)$ & Not stastically significant \\
\hline 2) Secondary school & $45(47)$ & 31 (33) & $76(80)$ & \\
\hline \multicolumn{5}{|l|}{ School attendance, $\mathbf{n}(\%)^{*}$} \\
\hline I) Regular/good & $3(3)$ & $3(3)$ & $6(6)$ & Pearson chi $^{2}=10.36, P=0.006$ \\
\hline 2) Low & $15(16)$ & $25(26)$ & $4(42)$ & \\
\hline 3) School abandonment & $35(37)$ & $14(15)$ & $49(52)$ & \\
\hline \multicolumn{5}{|l|}{ Parental disorders, n (\%)* } \\
\hline I) none & $38(40)$ & $31(33)$ & $69(73)$ & Not stastically significant \\
\hline 2) Psychiatric diseases & $8(8)$ & $12(13)$ & $20(2 I)$ & \\
\hline 3) Addictions & $2(2)$ & $0(0)$ & $2(2)$ & \\
\hline 4) Other diseases & $4(4)$ & $0(0)$ & $4(4)$ & \\
\hline \multicolumn{5}{|l|}{ Early life stressful events, n (\%) } \\
\hline I) none & $24(25)$ & $23(24)$ & $47(49)$ & Not stastically significant \\
\hline $\begin{array}{l}\text { 2) Parental abandonment, bereavement, } \\
\text { and/or social maladjustment }\end{array}$ & II (I2) & $10(11)$ & $2 \mathrm{I}(22)$ & \\
\hline 3) Economic problems & $8(8)$ & $7(7)$ & $15(16)$ & \\
\hline 4) More or other events & $9(5)$ & $3(3)$ & $12(13)$ & \\
\hline \multicolumn{5}{|l|}{ Child abuse, n (\%)* } \\
\hline I) none & $44(47)$ & $40(38)$ & $82(87.25)$ & Not stastically significant \\
\hline 2) Physical abuse & $5(5)$ & $2(2)$ & $7(7.5)$ & \\
\hline 3) Sexual abuse & $2(2)$ & $2(2)$ & $4(4.25)$ & \\
\hline 4) Others & $0(1)$ & $0(1)$ & $I(I)$ & \\
\hline \multicolumn{5}{|l|}{ Intellective level, n (\%)** } \\
\hline I) Normal & $45(49)$ & $36(40)$ & $81(89)$ & Not stastically significant \\
\hline 2) Lower in comparison to the range for age & $5(5)$ & $5(5)$ & $10(11)$ & \\
\hline \multicolumn{5}{|c|}{ Onset age of psychiatric pathology, mean \pm SD* } \\
\hline Years & $13.65 \pm 0.43$ & $14.19 \pm 0.30$ & $13.89 \pm 2.63$ & Not stastically significant \\
\hline \multicolumn{5}{|c|}{ Period of psychiatric treatment, mean \pm SD* } \\
\hline Years & $2.17 \pm 0.43$ & $1.70 \pm 0.36$ & $1.96 \pm 2.81$ & Not stastically significant \\
\hline
\end{tabular}

Notes: *Data available for 94 patients. **Data available for 91 patients.

Abbreviation: SD, standard deviation.

who presented poorer school performance, and females, who more often interrupted their schooling (Table 3).

The onset age of psychiatric disorders was just $>13$ years (on average 13.89 $\pm 2.63 \mathrm{SD}$ ), and the period of psychiatric treatment by CANPS was $\sim 2$ years on average (Table 3 ). Among the demographic variables and medical history of our patients, parental psychiatric illness was the only variable that presented a negative statistically significant correlation with the age of mental disorder onset in both the regression models (Table 4).
Our patients had 140 admissions to the SPDT of Nuovo Ospedale Civile Sant'Agostino Estense during the observation period (1.39 hospitalization per patient on average). The most frequent reason for admission to SPDT was represented by aggressive behavior, followed by suicide risk, acute psychotic decompensation, substance abuse, depressive state, psychosocial emergencies, and running away from home (Figure 1). The reasons for hospitalizations statistically significantly differed between males and females: early 
Table 4 The correlation between the onset age of psychiatric disorder and parental disorders in our sample $(n=10 \mathrm{I})$

\begin{tabular}{|c|c|c|c|c|}
\hline Variables* & Coefficient & Standard error & Probability & $\mathbf{9 5} \%$ confidence interval \\
\hline \multicolumn{5}{|l|}{ Single linear regression } \\
\hline Parental disorders vs none & -2.28 & 0.64 & $P<0.001$ & -3.53 to $1.0 \mathrm{I}$ \\
\hline \multicolumn{5}{|l|}{ Multiple linear regression } \\
\hline \multirow[t]{2}{*}{ Parental disorders* vs none } & -0.83 & 0.30 & $P=0.008$ & $0.23-1.43$ \\
\hline & Odds ratio & & & \\
\hline \multicolumn{5}{|l|}{ Single logistic regression } \\
\hline Parental disorders vs none & 4.39 & 2.51 & 0.010 & $1.43-13.47$ \\
\hline \multicolumn{5}{|l|}{ Multiple logistic regression } \\
\hline Parental disorders vs none & 4.21 & 2.90 & 0.027 & $1.09-16.24$ \\
\hline
\end{tabular}

Note: *Only statistically significant variables.

aggressive behavior was the most frequent cause for males, whereas suicide risk constituted the most frequent motivation for females (Pearson chi $^{2}=22.73, P=0.002$; Table 5 and Figure 1$)$. The majority of patients $(75.37 \%)$ were admitted to the SPDT after emergency department consultation and were voluntarily hospitalized (83.57\%), whereas $53.38 \%$ did not present a good therapeutic compliance (Table 5). During the observation period, the number of hospitalizations in SPDT progressively increased up to fivefold at the end of the observation period, with a transfer rate to "The Medlar" of $>60 \%$ during the last year (Figure 2). The most frequent psychiatric diagnosis at discharge from the SPDT was represented by "conduct disorder", followed by "adjustment disorder" (Table 6 and Figure 3), with a statistically significant difference between males, who most frequently suffered from "conduct disorder", and females, who more often presented "adjustment disorder" (Pearson $\mathrm{chi}^{2}=26.96$, $P=0.001$; Table 6 and Figure 3$)$. The addiction disorders were more frequent in males $(25.93 \%)$ than females $(10.17 \%)$, and the most frequent substance of abuse was cannabinoids, also associated with other substances ( $32 \%$ of our sample) (Table 6). Our sample had a low frequency of organic

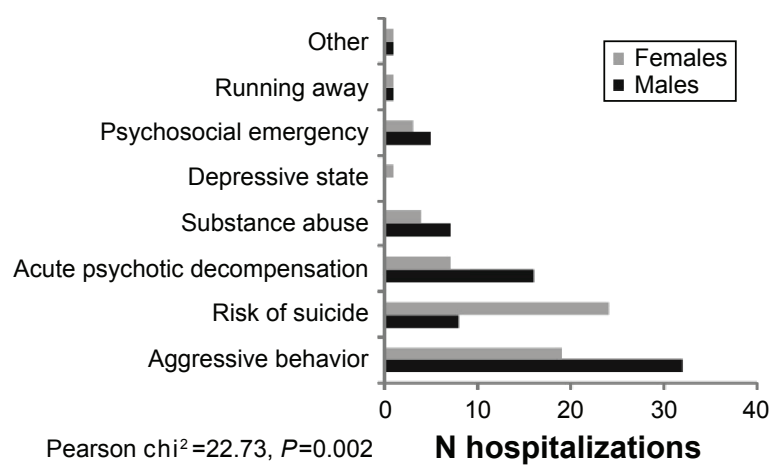

Figure I Reasons for hospitalizations in SPDT, divided by sex. Abbreviation: SPDT, Service of Psychiatric Diagnosis and Treatment. comorbidity (18.55\%), with no statistically significant differences by sex (Table 6).

We have found that 83 of the 140 hospitalizations in SPDT were transferred to "The Medlar" during the observation period. The clinical variables related to stays at "The Medlar" differed from those of SPDT hospitalizations for many features as provided by local guidelines: more prolonged period of hospitalization, more rehabilitation activities for all patients, lower level of aggressiveness, different pharmacological therapies, and destinations at discharge (Table 7). From "The Medlar", patients more frequently were sent home, with the support of the Day Hospital of CANPS and regular visits by referring specialists of CANPS, whereas, from SPDT, patients more frequently were transferred to "another ward or facility", in particular to "The Medlar" (Table 7). Both in SPDT and "The Medlar", mild and severe aggressive behavior was recorded with higher frequency in SPDT compared to that recorded in the facility (Table 7). At discharge, only a minority of patients were not prescribed a drug therapy, whereas in most cases, poly-pharmacy was administered (Table 7).

\section{Discussion}

Our study has revealed that the use of psychiatric hospitalization for adolescents has gradually but greatly increased since the availability of hospital beds in the acute psychiatric ward (SPDT) and in the protected facility ("The Medlar"). This result, although limited to a single town area, is in line with literature data which highlight the increase of psychiatric treatments in adolescents. ${ }^{3,21}$ In this regard, we have to emphasize that the availability of hospital beds dedicated to adolescents could have in itself increased the demand for hospitalization, indirectly shaping the treatment modality. Therefore, we cannot affirm whether the observed increase of adolescent psychiatric treatments represents an epidemiologic trend of adolescent psychiatric disorders or rather an 
Table 5 The clinical variables of our sample's hospitalizations in SPDT ( $n=\mid 40)$

\begin{tabular}{|c|c|c|c|c|}
\hline \multirow[t]{2}{*}{ Variables } & \multirow{2}{*}{$\frac{\text { Males }}{\mathrm{N}=8 \mathrm{I}(58 \%)}$} & \multirow{2}{*}{$\frac{\text { Females }}{N=59(42 \%)}$} & \multirow{2}{*}{$\begin{array}{l}\text { Total } \\
N=140(100 \%)\end{array}$} & \multirow[t]{2}{*}{ Statistical test } \\
\hline & & & & \\
\hline \multicolumn{5}{|l|}{ Reason for hospitalization, n (\%) } \\
\hline I) Aggressive behavior & $32(40)$ & $19(32.20)$ & $51(37.14)$ & \multirow[t]{8}{*}{ Pearson $\mathrm{chi}^{2}=22.73, P=0.002$} \\
\hline 2) Risk of suicide & $8(10)$ & $24(40.68)$ & $32(22.86)$ & \\
\hline 3) Acute psychotic decompensation & $16(20)$ & $7(11.86)$ & $23(16.43)$ & \\
\hline 4) Substance abuse & $7(21.25)$ & $4(6.78)$ & $2 \mid(\mid 5)$ & \\
\hline 5) Depressive state & $0(0)$ & I ( $(.7)$ & I (0.7I) & \\
\hline 6) Psychosocial emergency & $5(6.25)$ & $3(5.08)$ & $8(5.7 \mathrm{I})$ & \\
\hline 7) Running away & $\mathrm{I}(1.25)$ & I (I.69) & $2(1.43)$ & \\
\hline 8) Other & $\mathrm{I}(\mathrm{I} .25)$ & $0(0)$ & I (0.7I) & \\
\hline \multicolumn{5}{|l|}{ Therapeutic compliance at admission, $\mathbf{n}(\%)$} \\
\hline I) Absent & $4 \mathrm{I}(53.25)$ & $30(53.57)$ & 71 (53.38) & \multirow[t]{3}{*}{ Not stastically significant } \\
\hline 2) Present & $34(44.15)$ & $24(42.865)$ & $62(43.6 I)$ & \\
\hline 3) Discontinuous & $2(2.6)$ & $2(3.57)$ & $7(3)$ & \\
\hline \multicolumn{5}{|l|}{ Modality of hospitalization, $n$ (\%) } \\
\hline I) Voluntary treatment & $64(79.01)$ & $53(20.99)$ & $117(83.57)$ & \multirow[t]{2}{*}{ Not stastically significant } \\
\hline 2) Involuntary treatment & $17(89.83)$ & $6(10.17)$ & $23(16.43)$ & \\
\hline \multicolumn{5}{|l|}{ Modality of admission, $\mathbf{n}(\%)$} \\
\hline I) After ER consultant & $54(67)$ & $47(79.66)$ & I0I (72) & \multirow[t]{3}{*}{ Not stastically significant } \\
\hline 2) Transfer from "The Medlar" or from another ward & I8 (22) & $4(7.79)$ & $22(16)$ & \\
\hline 3) After CANPS consultant & $9(\mathrm{II})$ & $8(13.55)$ & $17(12)$ & \\
\hline
\end{tabular}

Abbreviations: SPDT, Service of Psychiatric Diagnosis and Treatment; ER, emergency room; CANPS, Childhood and Adolescence Neuro-Psychiatry Service.

enhanced opportunity for treating adolescent patients with psychiatric problems.

Our sample, although limited in number, was homogeneous for sex and age distribution and representative of our social environment. Among the demographics and medical histories, parental psychiatric illness was the only variable negatively related, in a statistically significant way, to the onset age of childhood mental disorders. This result shows that a family context with mental disorder can lead to an increased vulnerability for psychiatric illness in children and adolescents, which tends to occur earlier, suggesting

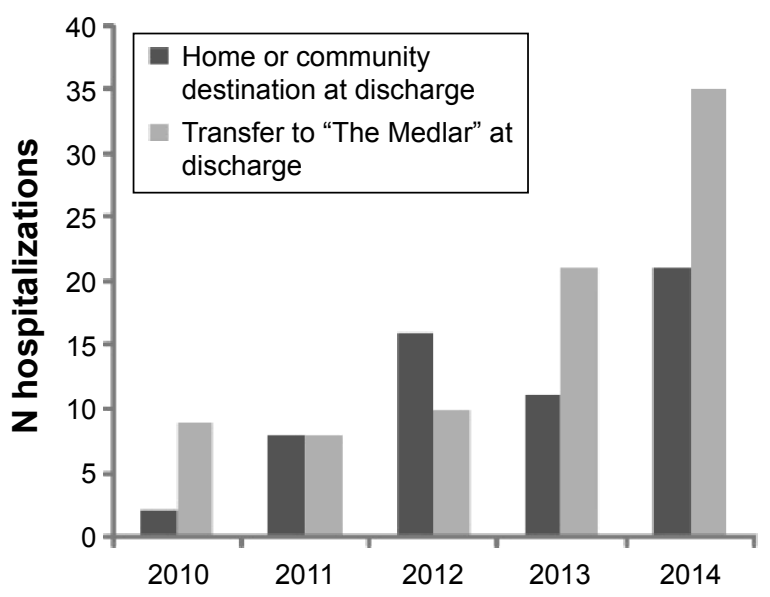

Figure 2 Destination at discharge of SPDT hospitalizations, by years of the observation period.

Abbreviation: SPDT, Service of Psychiatric Diagnosis and Treatment. strong parent conditioning on the development of childhood mental disorders. In any case, our data, which overlap most studies, cannot specify if this correlation is based on genetic or environmental factors or both.

Regarding family context, only $39 \%$ of our patients lived with both biological Italian parents, whereas the others lived with only one divorced parent, adoptive family, or immigrant family, or in institutions because they were abandoned or orphans. These data are in line with all the literature results, which highlight that early family changes, such as divorces or immigration, are potential risk factors for the development of a mental disorder in children..$^{31,32}$

About half of our patients reported in their histories stressful early life events, such as abandonment, economic difficulties, social exclusion, and physical and/or sexual abuse, although with lower percentages than other reports in the literature. ${ }^{36}$ Nevertheless, the high-impact emotional situations, as we reported, could represent such traumatic stress events as to condition the development of mental disorders, as observed by other authors. ${ }^{32,48}$ Despite their disadvantageous conditions, the adherence of our patients to treatments, as our high rate of voluntary treatments highlighted, was apparently good in comparison to another report. ${ }^{4}$ The majority of our patients had a normal intellective level, but, despite this, only $6 \%$ presented regular school performance. In most cases, school attendance was discontinuous or insufficient. In particular, with a statistically significant difference 
Table 6 Psychiatric diagnosis, substance abuse, and organic comorbidity at discharge of SPDT ( $n=140)$

\begin{tabular}{|c|c|c|c|c|}
\hline \multirow[t]{3}{*}{ Variables } & \multicolumn{3}{|l|}{ Sample } & \multirow[t]{3}{*}{ Statistical test } \\
\hline & \multirow{2}{*}{$\begin{array}{l}\text { Males } \\
\mathrm{N}=8 \mathrm{I}(58 \%)\end{array}$} & \multirow{2}{*}{$\frac{\text { Females }}{\mathrm{N}=59(42 \%)}$} & \multirow{2}{*}{$\frac{\text { Total }}{\mathrm{N}=140(100 \%)}$} & \\
\hline & & & & \\
\hline \multicolumn{5}{|c|}{ Psychiatric diagnosis at discharge (ICD-9-CM), n (\%) } \\
\hline $\begin{array}{l}\text { 1) Psychiatric disorders related to substance } \\
\text { abuse }(291-292.9 ; 303-305.9)\end{array}$ & $9(11.39)$ & I (I.72) & $10(7.24)$ & Pearson $\mathrm{chi}^{2}=26.97, P=0.00 \mathrm{I}$ \\
\hline $\begin{array}{l}\text { 2) Schizophrenia disorders and other psychoses } \\
(295-295.9 ; 298-299.9)\end{array}$ & $13(16.45)$ & $3(5.17)$ & $16(1.59)$ & \\
\hline 3) Bipolar disorders (296-296.9) & $2(2.53)$ & $5(8.62)$ & $7(5.07)$ & \\
\hline 4) Anxiety disorders and dysthymia (300-300.9) & $8(10.12)$ & $10(17.24)$ & $18(13.04)$ & \\
\hline 5) Personality disorders (30I-30I.9) & $13(16.45)$ & $9(|5.5|)$ & $22(15.94)$ & \\
\hline 6) Eating disorders (307.50-307.52) & $2(2.53)$ & $4(6.89)$ & $6(4.34)$ & \\
\hline 7) Adjustment disorders (308-309.9) & $6(7.59)$ & $17(29.31)$ & $23(16.66)$ & \\
\hline 8) Conduct disorders (3|2-3|2.9) & $23(29.11)$ & $7(12.06)$ & $30(22.46)$ & \\
\hline $\begin{array}{l}\text { 9) Neurodevelopmental disorders and mental } \\
\text { retardation }(3|5-3| 5.9 ; 3|7-3| 9)\end{array}$ & $3(3.79)$ & $2(3.44)$ & $5(3.62)$ & \\
\hline \multicolumn{5}{|l|}{ Substance abuse in comorbidity, $\mathbf{n}(\%)$} \\
\hline I) Absent & $47(58.02)$ & $45(76.27)$ & $92(65.7 I)$ & Not stastically significant \\
\hline 2) Alcohol & $2(2.47)$ & $0(0)$ & $2(1.43)$ & \\
\hline 3) Stimulants (cocaine) & $\mathrm{I}(\mathrm{I} .23)$ & $0(0)$ & $\mathrm{I}(0.7 \mathrm{I})$ & \\
\hline 4) Cannabinoids & $21(25.93)$ & $6(10.17)$ & $27(19.28)$ & \\
\hline 5) Opioids & $\mathrm{I}(\mathrm{I} .23)$ & $0(0)$ & $I(0.7 I)$ & \\
\hline 6) Other and/or more substances & $9(11.12)$ & $8(13.56)$ & $17(12.16)$ & \\
\hline \multicolumn{5}{|l|}{ Organic comorbidity, n (\%) } \\
\hline I) Absent & $49(83.05)$ & $30(78.94)$ & $122(81.44)$ & Not stastically significant \\
\hline 2) Present & $10(16.95)$ & $8(21.05)$ & $18(18.55)$ & \\
\hline
\end{tabular}

Abbreviations: ICD-9-CM, International Classification of Diseases, 9th Revision, Clinical Modification, Italian Version of 2007; SPDT, Service of Psychiatric Diagnosis and Treatment.

between sexes, males presented the worst school performance, whereas females more often interrupted school attendance. Our data suggest that a severe psychiatric condition, such as those suffered by our patients, could have a significant negative impact on school performance, regardless of cognitive level. Moreover, we have to underline that disadvantaged social conditions or stressful family context, such as those highlighted in our sample, could be unfavorable conditions for school attendance.

The main cause of SPDT hospitalization was represented by aggressive behavior, mainly for males, followed by the risk of suicide, more frequent in females. This result overlaps the sex difference reported by most studies which highlighted higher rates of suicide attempts in adolescent females. ${ }^{9,12-15,49}$

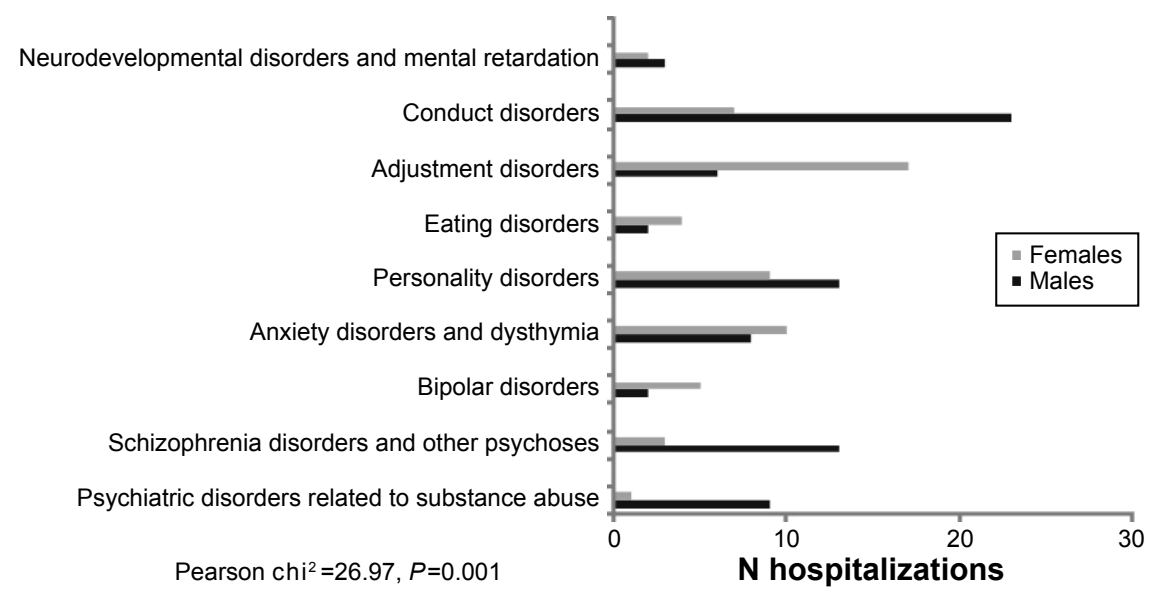

Figure 3 Psychiatric diagnosis at discharge from SPDT (ICD-9-CM), divided by sex.

Abbreviations: SPDT, Service of Psychiatric Diagnosis and Treatment; ICD-9-CM, International Classification of Diseases, 9th Revision, Clinical Modification, Italian Version of 2007. 
Table 7 The clinical variables of hospitalizations in SPDT and "The Medlar"

\begin{tabular}{|c|c|c|c|}
\hline \multirow[t]{2}{*}{ Variables } & \multirow{2}{*}{$\frac{\text { SPDT }}{N=140}$} & \multirow{2}{*}{$\frac{\text { The Medlar }}{\mathbf{N}=83}$} & \multirow[t]{2}{*}{ Statistical test } \\
\hline & & & \\
\hline \multicolumn{4}{|l|}{ Duration of hospitalization, mean \pm SD } \\
\hline Days & $5.82 \pm 5.67$ & $37.12 \pm 36.44$ & $t=-9.9757$, Student's $t$-test; $P=0.000$ \\
\hline \multicolumn{4}{|l|}{ Aggressive behavior, n (\%) } \\
\hline I) Absent & $47(34)$ & $54(65)$ & Pearson $\mathrm{chi}^{2}=58.1939, P=0.000$ \\
\hline 2) Present & $51(36)$ & $21(25)$ & \\
\hline 3) Severe with need for physical restraint and/or hospital security & $42(30)$ & $8(10)$ & \\
\hline \multicolumn{4}{|l|}{ Pharmacological therapy at discharge, n (\%) } \\
\hline I) None & $8(6)$ & $5(6)$ & Pearson $\mathrm{chi}^{2}=81.4456, P=0.000$ \\
\hline 2) Mono-therapy & $36(26)$ & $16(19)$ & \\
\hline 3) Poly-therapy & $96(69)$ & $62(75)$ & \\
\hline \multicolumn{4}{|l|}{ Destination at discharge, $\mathbf{n}(\%)$} \\
\hline I) Home with CANPS care & $41(29)$ & $49(59)$ & Pearson $\mathrm{chi}^{2}=88.793 \mathrm{I}, P=0.000$ \\
\hline 2) Day hospital of CANPS & $5(4)$ & $21(25)$ & \\
\hline 3) Community/protected facility & $12(9)$ & $10(12)$ & \\
\hline 4) Transfer to psychiatric ward or facility & $82(59)$ & $3(4)$ & \\
\hline \multicolumn{4}{|l|}{ Psychiatric drugs prescribed at discharge, n (\%) } \\
\hline I) Typical antipsychotics & $64(28)$ & $50(34)$ & Pearson $\mathrm{chi}^{2}=230.4705, P=0.000$ \\
\hline 2) Antidepressants & $28(12)$ & $18(12)$ & \\
\hline 3) Mood stabilizers & $36(16)$ & $25(17)$ & \\
\hline 4) Benzodiazepines & $56(24)$ & $25(17)$ & \\
\hline \multicolumn{4}{|l|}{ Psychotherapy, n (\%) } \\
\hline I) Individual & $130(93)$ & $77(93)$ & Not stastically significant \\
\hline 2) Familial & $10(7)$ & $6(7)$ & \\
\hline \multicolumn{4}{|l|}{ Rehabilitative programs, n (\%) } \\
\hline I) No rehabilitation programs & $69(49)$ & $0(0)$ & Pearson $\mathrm{chi}^{2}=28.2487, P=0.000$ \\
\hline 2) To general functioning & $7 I(5 I)$ & $52(63)$ & \\
\hline 3) To specific performances & $0(0)$ & $31(37)$ & \\
\hline
\end{tabular}

Abbreviations: SPDT, Service of Psychiatric Diagnosis and Treatment; SD, standard deviation; CANPS, Childhood and Adolescence Neuro-Psychiatry Service.

Regarding the sex difference, we observed that the diagnosis of conduct disorder with aggressive and impulsive behavior was prevalent in males, whereas in females, maladjustment reaction with depressive mood and anxiety disorders was the most frequent diagnosis at discharge. Our results indirectly are in line with other studies which highlight a correlation between male sex and aggressiveness due to testosterone hormonal profile, although this relationship might represent an "oversimplification" of a complex human behavior, such as aggressiveness..$^{50,51}$

Although substance abuse was prevalent in males, representing for them a frequent reason for hospitalization, we have not observed any statistically significant sex difference. In males and females, cannabinoids use, single or in combination with other substances, was the most common abuse.

In both SPDT and "The Medlar", we recorded mild and severe aggressive behavior of patients admitted, without any sex difference, with a rate almost double in SPDT in comparison to the residential facility. The difference between the two structures could be related to the acute phase of the patients admitted to the SPDT, successively transferred in subacute phase to "The Medlar" for continuation of care. In line with the local guidelines, all patients in the sample had brief hospitalizations in SPDT, which were continued in more than half of the cases in "The Medlar". In this facility, they were hospitalized longer with more structured psychotherapeutic and rehabilitative programs extended to all patients admitted.

\section{Conclusion}

The psychiatric hospitalization of adolescents is an increasing worldwide phenomenon, described only in few studies and still little studied, especially in Italy, where the literature on this topic is very poor. Our study, which puts in evidence similar trend in psychiatric hospitalizations of adolescents, contributes to analyze this issue. The main limits of this study consist of its retrospective design, limited to only one local health area, with a sample not sufficiently large to permit definitive and generalized conclusions.

The analysis of our anamnestic data revealed some important elements, such as the negative statistically significant correlation between parental psychiatric illness and onset age 
of mental disorders, as well as the high frequency of stressful early life events in the history of our patients.

Concerning the sex difference, we evidenced that the aggressive behavior in males, mainly suffered from conduct disorders, and suicide attempt in females, were the most frequent reasons for hospitalization, confirming the clinical observation of different sex vulnerability.

More studies are needed to explore the relationship between the risk factors and the onset of psychiatric illness in children. More attention is necessary to correctly implement health programs for acute situations in order to permit early treatments for young patients, ensuring that they have as normal a development as possible.

We conclude by saying that, even in the case of the adolescent patients, psychiatric treatment must be not only pharmacological but also relational and rehabilitative.

\section{Disclosure}

The authors declare no financial interest or benefit has arisen from the direct applications of this research.

\section{References}

1. American Academy of Pediatrics, Committee on Pediatric Emergency Medicine; American College of Emergency Physicians and Pediatric Emergency Medicine Committee; Dolan MA, Mace SE. Pediatric mental health emergencies in the emergency medical services system. Pediatrics. 2006;118(4):1764-1767.

2. Hamm MP, Osmond M, Curran J, et al. A systematic review of crisis interventions used in the emergency department: recommendations for pediatric care and research. Pediatr Emerg Care. 2010;26(12):952-962.

3. Pittsenbarger ZE, Mannix R. Trends in pediatric visits to the emergency department for psychiatric illnesses. Acad Emerg Med. 2014;21(1): 25-30.

4. Lamb CE. Alternatives to admission for children and adolescents: providing intensive mental healthcare services at home and in communities: what works? Curr Opin Psychiatry. 2009;22(4):345-350.

5. Mahajan P, Alpern ER, Grupp-Phelan J, et al; for Pediatric Emergency Care Applied Research Network (PECARN). Epidemiology of psychiatric-related visits to emergency departments in a multicenter collaborative research pediatric network. Pediatr Emerg Care. 2009; 25(11):715-720.

6. Timlin U, Hakko H, Riala K, Räsänen P, Kyngäs H. Adherence of 13-17 year old adolescents to medicinal and non-pharmacological treatment in psychiatric inpatient care: special focus on relative clinical and family factors. Child Psychiatry Hum Dev. 2015;46(5):725-735.

7. Chun TH, Katz ER, Duffy SJ. Pediatric mental health emergencies and special health care needs. Pediatr Clin North Am. 2013;60(5): 1185-1201.

8. Nock MK, Borges G, Bromet EJ, Cha CB, Kessler RC, Lee S. Suicide and suicidal behavior. Epidemiol Rev. 2008;30:133-154.

9. Dolan MA, Fein JA; for Committee on Pediatric Emergency Medicine. Pediatric and adolescent mental health emergencies in the emergency medical services system. Pediatrics. 2011;127(5):e1356-e1366.

10. Brent DA, McMakin DL, Kennard BD, Goldstein TR, Mayes TL, Douaihy AB. Protecting adolescents from self-harm: a critical review of intervention studies. J Am Acad Child Adolesc Psychiatry. 2013;52(12): 1260-1271.
11. Klimes-Dougan B, Klingbeil DA, Meller SJ. The impact of universal suicide-prevention programs on the help-seeking attitudes and behaviors of youths. Crisis. 2013;34(2):82-97.

12. Janssens A, Hayen S, Walraven V, Leys M, Deboutte D. Emergency psychiatric care for children and adolescents: a literature review. Pediatr Emerg Care. 2013;29(9):1041-1050.

13. Nock MK, Green JG, Hwang I, et al. Prevalence, correlates, and treatment of lifetime suicidal behavior among adolescents: results from the National Comorbidity Survey Replication Adolescent Supplement. JAMA Psychiatry. 2013;70(3):300-310.

14. Boyer L, Henry JM, Samuelian JC, et al. Mental disorders among children and adolescents admitted to a French psychiatric emergency service. Emerg Med Int. 2013;2013:651530.

15. Sangermani R. Problemi di salute mentale nell'infanzia e nell'adolescenza: criticità nella pratica e nella modalità di intervento. [Mental health problems in childhood and adolescence: issues in clinical practice and modality of intervention] Quaderni Acp. 2014;21(5): 210-213.

16. Hage S, Van Meijel B, Fluttert F, Berden GF. Aggressive behaviour in adolescent psychiatric settings: what are risk factors, possible interventions and implications for nursing practice? A literature review. J Psychiatr Ment Health Nurs. 2009;16(7):661-669.

17. Murray CL, Lopez AD. The global burden of disease. A comprehensive assessment of mortality and disability from diseases, injuries, and risk factors in 1990 and projected to 2020. Harvard University Press; 1996. Available from: http://apps.who.int/iris/bitstream/10665/41864/1/096 5546608_eng.pdf. Accessed August 5, 2015.

18. Kessler RC, Amminger GP, Aguilar-Gaxiola S, Alonso J, Lee S, Ustün TB. Age of onset of mental disorders: a review of recent literature. Curr Opin Psychiatry. 2007;20(4):359-364.

19. Douglass AM, Luo J, Baraff LJ. Emergency medicine and psychiatry agreement on diagnosis and disposition of emergency department patients with behavioral emergencies. Acad Emerg Med. 2011;18(4): 368-373.

20. Jones PB. Adult mental health disorders and their age at onset. Br J Psychiatry Suppl. 2013;54:s5-s10.

21. Pullmann MD. Participatory research in systems of care for children's mental health. Am J Community Psychol. 2009;44(1-2):43-53.

22. Merikangas KR, He JP, Burstein M, et al. Service utilization for lifetime mental disorders in U.S. adolescents: results of the National Comorbidity Survey-Adolescent Supplement (NCS-A). J Am Acad Child Adolesc Psychiatry. 2011;50(1):32-45.

23. Chun TH, Duffy SJ, Linakis JG. Emergency department screening for adolescent mental health disorders: the who, what, when, where, why and how it could and should be done. Clin Pediatr Emerg Med. 2013; 14(1):3-11.

24. Pottick KJ, McAlpine DD, Andelman RB. Changing patterns of psychiatric inpatient care for children and adolescents in general hospitals, 1988-1995. Am J Psychiatry. 2000;157(8):1267-1273.

25. Merikangas KR, He JP, Burstein M, et al. Lifetime prevalence of mental disorders in U.S. adolescents: results from the National Comorbidity Survey Replication - Adolescent Supplement (NCS-A). J Am Acad Child Adolesc Psychiatry. 2010;49(10):980-989.

26. Mino A, Bousquet A, Broers B. Substance abuse and drug-related death, suicidal ideation, and suicide: a review. Crisis. 1999;20(1):28-35.

27. Hetherington EM, Stanley-Hagan M. The adjustment of children with divorced parents: a risk and resiliency perspective. J Child Psychol Psychiatry. 1999;40(1):129-140.

28. Bridge JA, Goldstein TR, Brent DA. Adolescent suicide and suicidal behavior. J Child Psychol Psychiatry. 2006;47(3-4):372-394.

29. Morgan C, Fisher H. Environment and schizophrenia: childhood trauma - a critical review. Schizophr Bull. 2007;33(1):3-10.

30. Walsh F. Traumatic loss and major disasters: strengthening family and community resilience. Fam Process. 2007;46(2):207-227.

31. Pumariega AJ, Rothe E. Cultural considerations in child and adolescent psychiatric emergencies and crises. Child Adolesc Psychiatr Clin N Am. 2003;12(4):723-744, vii. 
32. Marcelli D, Bertheut E. Urgences Psychiatriques à l'adolescence. Rev Prat. 2003;53:1191-1196.

33. American Academy of Child and Adolescent Psychiatry. Inpatient hospital treatment of children and adolescents; 1989. Available from: https://www.aacap.org/aacap/policy_statements/1989/ Inpatient_Hospital_Treatment_of_Children_and_Adolescents.aspx. Accessed August 5, 2015.

34. Committee on State and Community Psychiatric Systems of the Council on Psychiatric Services. American Psychiatric Association. Guidelines for psychiatric practice in public sector psychiatric inpatient facilities. Am J Psychiatry. 1994;151(5):797-798.

35. Royal College of Psychiatrists. Acute in-patient psychiatric care for young people with severe mental illness. Recommendations for commissioners, child and adolescent psychiatrists and general psychiatrists. Council Report CR106. June 2002. Available from: http://www.rcpsych. ac.uk/files/pdfversion/cr106.pdf. Accessed August 5, 2015.

36. Kendall T, Pilling S, Whittington C, Pettinari C, Burbeck R. Clinical Guidelines in Mental Health II: a guide to making NICE Guidelines. Psychiatrist. 2005;29(1):3-8.

37. Edelsohn GA, Gomez JP. Psychiatric emergencies in adolescents. Adolesc Med Clin. 2006;17(1):183-204.

38. Fondazionechild.it [homepage on the internet]. Florence Declaration. Mental wellbeing of children in Europe Plans and perspectives. In: XIII ESCAP Congress Florence; August 25-29, 2007; Italy. Available from: http://www.fondazionechild.it/layout/upload/ FLORENCE_DECLARATION.pdf. Accessed August 5, 2015.

39. Calderoni DI, Ferrara M, Sarti M, Nardocci F. "More With Less": minorie ricovero psichiatrico. Giorn Neuropsich Età Evol. 2008;28:149-166.

40. Normativasan.servizirl.it [homepage on the internet]. Regione Lombardia - Direzione Generale Sanità, Report relativo ai ricoveri extra-contratto 2010, nota della D.G. Sanità del 04/06/2012, prot. H1.2012.0017581. Available from: http://normativasan.servizirl.it/port/ GetNormativaFile?fileName=3660_Ricoveri extracontratto psichiatria e NPIA 2010.doc. Accessed August 5, 2015.

41. Sinpia.eu [homepage on the internet]. Coordinamento Regionale di Neuropsichiatria Infantile (NPI). Assessorato alla sanità-regione Piemonte. Regione Piemonte. Emergenza psichiatrica in età evolutiva programma di governo clinico per i disturbi neuropsichiatrici in età evolutiva; 2011. Available from: www.sinpia.eu/regionali/sezione/ cat/37/page/documenti. Accessed August 5, 2015.
42. Ars.toscana.it [homepage on the internet]. La salute mentale in Toscana: aggiornamenti e sviluppi. Documenti dell'Agenzia Regionale di Sanità della Toscana, 68, 2012. Available from: https://www.ars.toscana.it/ files/pubblicazioni/Volumi/2012/68_salute_mentale.pdf. Accessed August 5, 2015.

43. Pedrini L, Colasurdo G, Costa S, et al; for PREMIA Group. The characteristics and activities of child and adolescent mental health services in Italy: a regional survey. BMC Psychiatry. 2012;12:7.

44. Istat.it [homepage on the internet]. ISTAT L'ospedalizzazione di pazienti affetti da disturbi psichici; 2009. Available from: http://www istat.it/it/archivio/10130/. Accessed August 5, 2015.

45. Gruppo di lavoro per la convenzione sui diritti dell'Infanzia e dell' Adolescenza. I diritti dell'infanzia e dell'adolescenza in Italia. $8^{\circ}$ Rapporto di aggiornamento sul monitoraggio della Convenzione sui diritti dell'infanzia e dell'adolescenza in Italia, anno 2014-2015. 30 aprile 2015. Gruppo CRC Roma. Available from: http://gruppocrc. net/IMG/pdf/VIIIrapportoCRC.pdf. Accessed August 5, 2015.

46. Ministero del Lavoro, della Salute e delle Politiche Sociali. La Classificazione delle Malattie, dei Traumatismi, degli Interventi Chirurgici e delle Procedure Diagnostiche e Terapeutiche: Versione Italiana della ICD-9-CM [International Classification of Diseases, 9th Revision, Clinical Modification, 2007]. Rome, Italy: Istituto Poligrafico e Zecca dello Stato, Libreria dello Stato; 2008. Italian.

47. Stata Corp LP. Stata Statistical Software: Release 12. College Station, TX: Stata Corp LP; 2011.

48. Spidel A, Lecomte T, Greaves C, Sahlstrom K, Yuille JC. Early psychosis and aggression: predictors and prevalence of violent behaviour amongst individuals with early onset psychosis. Int $J$ Law Psychiatry. 2010;33(3):171-176.

49. Rhodes AE, Bethell J, Carlise C, Rosychuk RJ, Lu H, Newton A. Time trends in suicide-related behaviours in girls and boys. Can J Psychiatry. 2014;59(3):152-159.

50. Carré JM, Olmstead NA. Social neuroendocrinology of human aggression: examining the role of competition-induced testosterone dynamics. Neuroscience. 2015;286:171-186.

51. Reimers L, Diekhof EK. Testosterone is associated with cooperation during intergroup competition by enhancing parochial altruism. Front Neurosci. 2015;9:183.
Neuropsychiatric Disease and Treatment

\section{Publish your work in this journal}

Neuropsychiatric Disease and Treatment is an international, peerreviewed journal of clinical therapeutics and pharmacology focusing on concise rapid reporting of clinical or pre-clinical studies on a range of neuropsychiatric and neurological disorders. This journa is indexed on PubMed Central, the 'PsycINFO' database and CAS,

\section{Dovepress}

and is the official journal of The International Neuropsychiatric Association (INA). The manuscript management system is completely online and includes a very quick and fair peer-review system, which is all easy to use. Visit http://www.dovepress.com/testimonials.php to read real quotes from published authors. 